\title{
Mathematical Models for Wind-Aided Flame Spread of Floor Coverings
}

\author{
P. VAN HEES \\ SP (Swedish National Testing and Research Institute), Fire Technology \\ Box 857, SE-501 15 Borås, Sweden \\ P. VANDEVELDE \\ University of Gent, Laboratory for Heat Transfer and Fuel Technology \\ Ottergemsesteenweg 711, BE-9000 Gent, Belgium
}

\begin{abstract}
Recently the fire hazard of floor coverings in a wind-aided flame spread scenario was shown in an extensive series of full scale and small scale tests. This paper describes two types of mathematical models used in this work for the prediction of wind-aided flame spread on floor coverings. Both models use cone calorimeter data as input. The first model gives the analytical solution for the flame spread as a function of time. This model can be used for a specific scenario and gives a good estimate of the possible risk of the floor covering. The second model is a numerical simulation model which allows the user to calculate the flame spread in a wider range of situations. This model can be used in the future for implementation in zone- or field models as input for the growth of the fire as a function of time. Both models show an acceptable degree of prediction level of the available full scale test results for floor coverings in a room corridor scenario. These full scale test results comprise most known families of floor coverings.
\end{abstract}

KEY WORDS: mathematical modelling, floor covering, wind-aided flame spread, heat release, cone calorimeter

\section{INTRODUCTION}

As mathematical modelling of fire phenomena gains importance, it has been used in ever increasing numbers of applications [1]. Up till recently only limited work has been done in applying this approach to commercially available floor coverings. Successful modelling of upward flame spread in wall linings, however, prompted an in-depth experimental and theoretical study of flame spread of floor coverings. The experimental data found in reference 
[2] has provided the basis for the development of two types of mathematical models of flame spread of floor coverings. The results of small scale tests have been used as input with an acceptable level of prediction of large scale results. These two mathematical models will be presented in this paper while an overview of related work is presented in reference [3]. Figure 1 shows how these models have been used in a flow diagram approach to research the risk assessment of wind-aided flame spread on floor coverings.

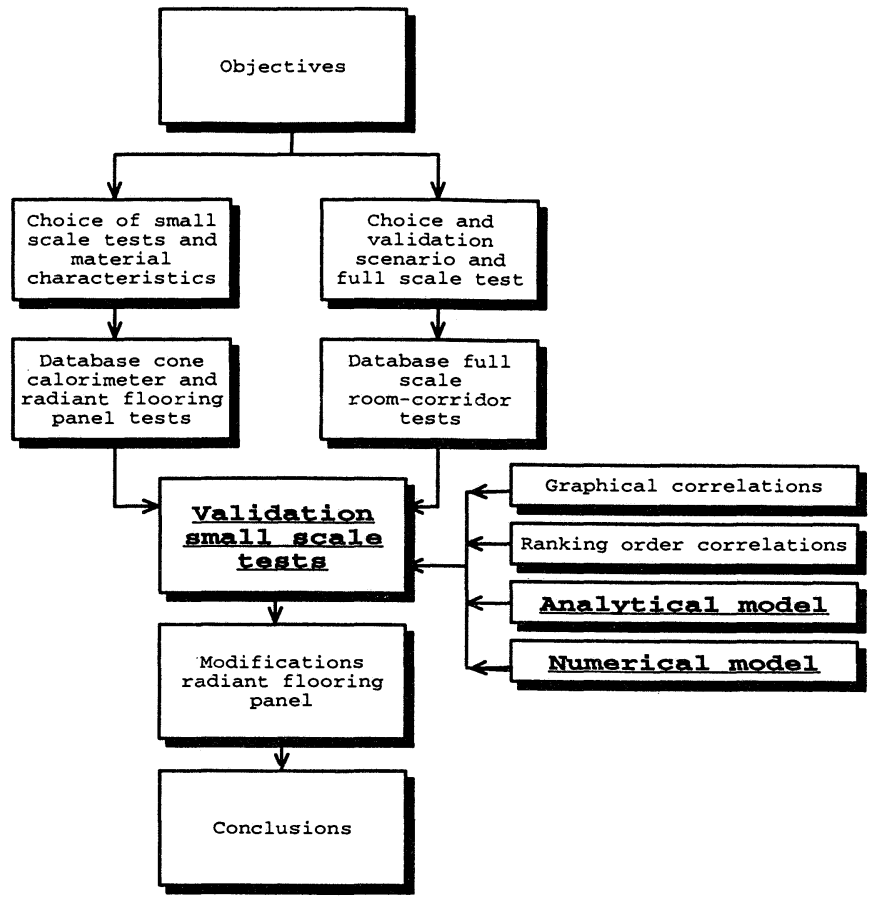

FIGURE 1: Position of the mathematical models within the research of wind-aided flame spread of floor coverings.

\section{ANALYTICAL MODEL FOR WIND-AIDED FLAME SPREAD OF FLOOR COVERINGS}

\section{Description}

This model will result in the pyrolysis distance as a function of time for a wind-aided configuration. A similar approach has been performed for the upward flame spread of wall linings [4], [5], [6]. Until now this approach has not been applied to horizontal wind-aided flame spread on a wide range of floor coverings in a room corridor scenario. Figure 2 shows a schematic picture of the geometry of this model. 


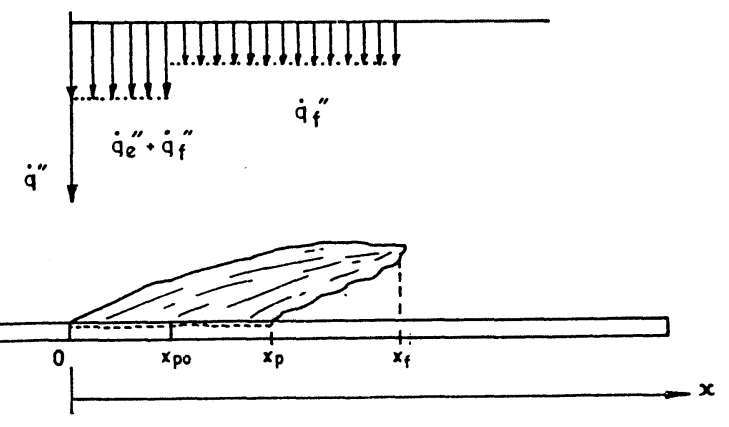

FIGURE 2: Description of horizontal wind-aided flame spread.

The following assumptions are made in this analytical model :

(i) The material is considered to be thermally thick.

(ii) The heat flux of the flame, $\dot{q}_{f}{ }^{\prime \prime}$, is constant for the area $x \leq x_{f}$ and zero for $x>x_{f}$.

(iii) The heat flux of the thermal attack, $\dot{q}_{e}{ }^{\prime}$, is constant for the area $0<x<x_{p o}$. In this area the material will ignite after a time equal to the ignition time at a uniform heat flux $\dot{q}_{e} "$.

(iv) Radiation from the hot smoke gases is included in the thermal attack for the area $0<$ $x<x_{p o}$, equal to the distance of floor coverings in the room.

(v) Between the heat release and the length of the flame, the following linear relationship can be used:

$$
\frac{x_{f}}{x_{p}}=k_{f} \dot{E}^{\prime \prime}
$$

(vi) The amount of combustible flooring material is limited with the exception of some wooden floor coverings. Hence it is necessary to take into account an extinction time of the material due to the fact that all material will be consumed after a time defined as $t_{b o}$. So the solution of the problem is divided into two periods.

For flame spread of floor coverings, the heat flux of the thermal attack, $\dot{q}_{e}{ }^{\prime \prime}$, in a real situation is mainly the radiation from the hot smoke gases under the ceiling. Assumption (iv) takes into account the fact that the heat flux of the thermal attack is limited to the area in the room covered with floor covering. Hence one can determine the moment the floor covering in the room ignites and whether there is flame spread towards the end of the corridor.

The constant cited in equation (1) is the flame length factor. In the literature an empirically determined value of $k_{f}=0.01 \mathrm{~m}^{2} / \mathrm{kW}$ is assumed for a linear relationship [6] in case of vertical flame spread. Although for the horizontal orientation the value might depend on the angle between the flame and the floor covering, we will use this value of $k_{f}$ as a worst case calculation. The first period defined in assumption (vi) is from time zero until the moment 
that the material which ignited in the initial area (distance $\left.x_{p o}\right)$ is extinguished $\left(0<t<t_{b o}\right)$. The pyrolysis front speed for this period can be written as [4]:

$\frac{d x_{p}}{d t} \cong \frac{x_{p}\left(t+t_{i g}\right)-x_{p}(t)}{t_{i g}}=\frac{x_{f}(t)-x_{p}(t)}{t_{i g}}$

where $t_{i g}$ is equal to the ignition time of the material determined for example in the cone calorimeter at 25 or $35 \mathrm{~kW} / \mathrm{m}^{2}$. The second period starts when the initial surface is extinguished $\left(t>t_{b o}\right)$. For this case the net increase of the pyrolysis can be calculated as the difference between the velocity of the pyrolysis front $\left(v_{p}(t)\right)$ and the velocity of the extinction front $\left(v_{b}(t)\right)[4]$ :

$v_{p}(t)-v_{b}(t)=\frac{d}{d t}\left(x_{p}-x_{b}\right)=\left(\frac{x_{f}(t)-x_{p}(t)}{t_{i g}}\right)-\left(\frac{x_{p}(t)-x_{b}(t)}{t_{b o}}\right)$

The extinction time $t_{b o}$ is also determined by means of small scale data, namely the cone calorimeter. Considering these two periods the analytical solution then becomes :

1) $\quad$ For $O<t<t_{b o}$

Inserting equation (1) into equation (2) yields:

$$
\frac{d x_{p}}{d t}=\left(k_{f} \dot{E}^{\prime \prime}-1\right) \frac{x_{p}}{t_{i g}}
$$

This equation can be integrated using the initial condition that at $t=0, x_{p}=x_{p o}$. The solution is then :

$x_{p}=x_{p o} \exp \left[\frac{\left(k_{f} \dot{E}^{\prime \prime}-1\right) t}{t_{\text {ip }}}\right]$

Thus, the flame spread will accelerate if $k_{f} \dot{E}^{\prime \prime}>1$ which implies that above a certain heat release acceleration will occur.

2) For $t>t_{b o}$

In this case the non-dimensional flame length is equal to:

$\left(\frac{x_{f}-x_{b}}{x_{p}-x_{b}}\right)=k_{f} \dot{E}^{\prime \prime}$

Combining equations (3) and (6) one obtains:

$\frac{d}{d t}\left(x_{p}-x_{b}\right)=\left(x_{p}-x_{b}\right)\left[\frac{\left(k_{f} \dot{E}^{\prime \prime}-1\right) \cdot t_{b_{0}}-t_{i g}}{t_{i g} \cdot t_{b o}}\right]$

This equation can be integrated using the initial condition that for $t=t_{b o},\left(x_{p}-x_{b}\right)=\left(x_{p l}-x_{p o}\right)$. The length of the pyrolysis zone then becomes:

$\left(x_{p}-x_{h}\right)=\left(x_{p l}-x_{p o}\right) \exp \left[\left(k_{f} \dot{E}^{\prime \prime}-\frac{t_{i g}}{t_{b o}}-1\right) \frac{\left(t-t_{b o}\right)}{t_{i g}}\right]$

and the risk for an acceleration of the flame spread depends now on three factors:

a) the normalised flame length, $\frac{\left(x_{f}-x_{b}\right)}{\left(x_{p}-x_{b}\right)}$, given by (6) which is a linear function of $\dot{E}^{\prime \prime}$;

b) the ignition time, $t_{i g}$;

c) the burning time of the material, $t_{b o}$.

If $\left(k_{f} \dot{E}^{\prime \prime}-\frac{t_{i g}}{t_{h o}}\right)>1$, then the flame spread will accelerate otherwise the extinction front will catch the pyrolysis front and the floor covering will extinguish. 


\section{Results and discussion}

To apply the analytical expression determined above we need three parameters. We will use the following values:

a) To determine the flame height, the average rate of heat release (AHRR) in the cone calorimeter is used for $\dot{E}^{\prime \prime}$. The value for $k_{f}$ is taken as $0.01 \mathrm{~m}^{2} / \mathrm{kW}$ being the most severe condition. If necessary this value can be adopted as a function of the angle between flame and surface.

b) The ignition time in the cone calorimeter is chosen at a certain heat flux level for $t_{i g}$.

c) The burning time in the cone calorimeter is chosen at a certain heat flux level for $t_{b o}$.

An overview of these parameters is summarised in table 1 for flux levels of $25 \mathrm{~kW} / \mathrm{m}^{2}$ and 35 $\mathrm{kW} / \mathrm{m}^{2}$. The shaded areas denote values greater than 1 , an '*' corresponds to no ignition, $\mathrm{C}_{\mathbf{i}}$ represents the exponent in equation (5), and $C_{b}$ the exponent in equation (8).

\begin{tabular}{|c|c|c|c|c|}
\hline Material & $\begin{array}{c}\mathrm{C}_{\mathrm{i}} \\
25 \mathrm{~kW} / \mathrm{m}^{2}\end{array}$ & $\begin{array}{c}C_{b} \\
25 \mathrm{~kW} / \mathrm{m}^{2}\end{array}$ & $\begin{array}{c}C_{i} \\
35 \mathrm{~kW} / \mathrm{m}^{2}\end{array}$ & $35 \mathrm{~kW} / \mathrm{m}^{2}$ \\
\hline PVC 1 & $*$ & * & 0.4500 & -0.0175 \\
\hline PVC 2 & 1.1900 & 0.7015 & 1.0100 & 0.6531 \\
\hline PVC 3 & 0.8600 & 0.7002 & 0.9300 & 0.8412 \\
\hline PVC 4 & 0.8800 & 0.6230 & 1.1100 & 0.9188 \\
\hline PVC 5 & 0.8700 & 0.5181 & 0.9900 & 0.7836 \\
\hline Linoleum & 1.6900 & 1.0794 & 1.9200 & 1.5490 \\
\hline Parquet 1 & 0.7500 & 0.4789 & 1.1100 & 0.9807 \\
\hline Parquet 2 & 0.6300 & 0.4934 & 0.8200 & 0.7581 \\
\hline Parquet 3 & 1.2400 & 0.7125 & 1.6700 & 1.2506 \\
\hline Cork FR & 0.4300 & 0.3023 & 0.6400 & 0.6080 \\
\hline Carpet 1 & 1.3100 & 0.3018 & 2.0100 & 1.6518 \\
\hline Carpet 2 & 1.3200 & -1.5467 & 1.9500 & 1.3884 \\
\hline Carpet 3 & 0.4300 & 0.1116 & 1.1500 & 1.0278 \\
\hline Carpet 4 & 1.6900 & 1.1584 & 2.4200 & 2.1758 \\
\hline Carpet 5 & 1.7000 & 0.6946 & 2.2500 & 1.8237 \\
\hline Carpet 6 & 1.4900 & 1.0242 & 1.9700 & 1.8217 \\
\hline Rubber & 0.7500 & 0.2621 & 0.9600 & 0.7308 \\
\hline
\end{tabular}

For a heat flux level of $25 \mathrm{~kW} / \mathrm{m}^{2}, 8$ materials have $C_{i}>1$. All materials causing flashover are included in these 8 as can seen in figure 3. Figure 3 gives a graphical overview for this parameter indicating at the same time the materials causing flashover (represented by the black boxes). Only PVC 2 and Carpet 1 are expected to show an increasing flame front in contradiction to the full scale tests [2]. However most floor coverings only burn during a short period and hence one should also investigate the parameter $C_{b}$. We can note that for 25 
$\mathrm{kW} / \mathrm{m}^{2}$ three materials have an exponent greater than 1 . This will mean that after extinction of the material in the room the pyrolysis front will decrease as can be seen in figure 4 for three selected materials. In this figure we also observe a slow acceleration for the materials causing flashover. In the full scale test the flame spread was considerably faster and of the order of $0.1 \mathrm{~m} / \mathrm{s}$ (table 2 ).

Considering the $35 \mathrm{~kW} / \mathrm{m}^{2}$ flux level, $C_{i}$ is more severe although $C_{b}$ shows more materials with an increasing flame spread after burnout of the initial surface. Also the flame spread acceleration corresponds better with the full scale results (figure 5, table 2 and reference [2]). Taking into account that the model starts with certain assumptions and that it is mainly limited to one specific scenario we can conclude that one can already determine which floor coverings might represent a risk in a wind-aided scenario.

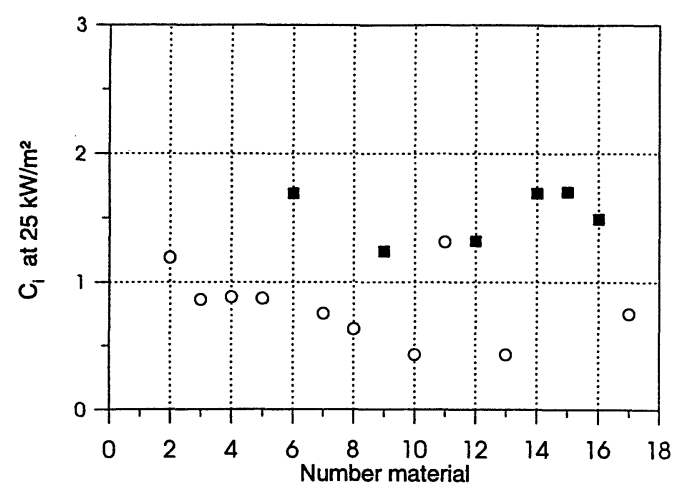

FIGURE 3: Graphical overview of parameter $C_{i}$ at $25 \mathrm{~kW} / \mathrm{m}^{2}$ in the cone calorimeter.

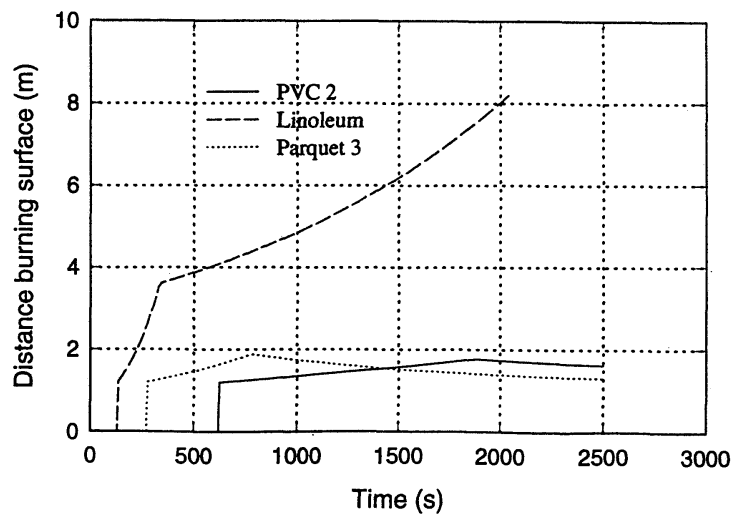

FIGURE 4: Calculated flame spread as a function of time for three materials by means of parameters determined at $25 \mathrm{~kW} / \mathrm{m}^{2}$ in the cone calorimeter. 


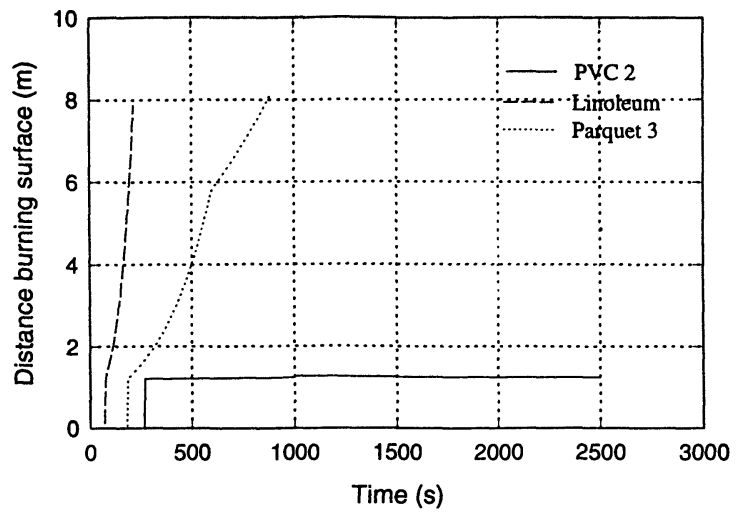

FIGURE 5: Calculated flame spread as a function of time for three materials using the parameters at $35 \mathrm{~kW} / \mathrm{m}^{2}$ in the cone calorimeter.

\section{NUMERICAL MODEL FOR WIND-AIDED FLAME SPREAD OF FLOOR COVERINGS}

\section{Description}

This model allows the user to perform predictions for the wind-aided flame spread of floor coverings using a flexible numerical approach. In this model the material is subdivided into $n$ numerical strips with a width of $\Delta x$. Each strip $i$ receives a total heat flux $\dot{q}_{t, i}{ }^{\prime \prime}$. If we assume that the heat conduction between the strips is zero we can solve this problem one dimensionally. A schematical view of the geometric basis of this model is given in figure 6 .

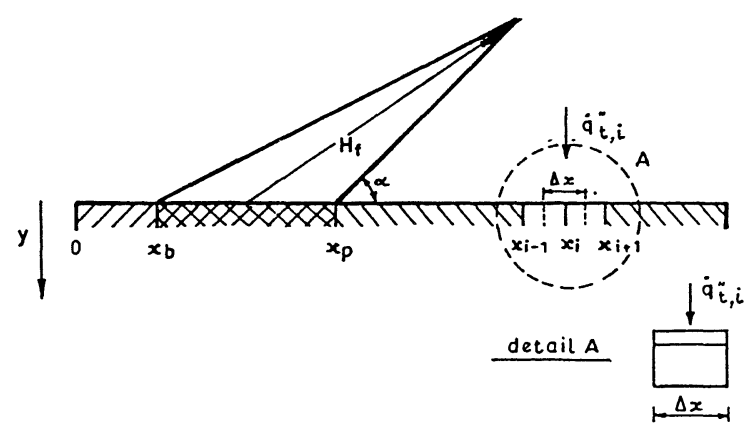

FIGURE 6. Schematical view of the numerical flame spread model. 
The total heat flux, $\dot{q}_{t, i}{ }^{\prime \prime}$, is calculated as follows:

$$
\dot{q}_{t, i}{ }^{\prime \prime}=\dot{q}_{f, i}{ }^{\prime \prime}+\dot{q}_{e, i}{ }^{\prime \prime}+\dot{q}_{c, i}{ }^{\prime \prime}+\dot{q}_{c o, i}{ }^{\prime \prime}+\dot{q}_{r, i}{ }^{\prime \prime}
$$

Thus, the heat transfer equation for each strip is[8]:

$$
\frac{\partial T}{\partial t}=\frac{k}{\rho c} \frac{\partial^{2} T}{\partial y^{2}}
$$

using the following initial and boundary conditions :

$$
t=0 \rightarrow T=T_{\infty} \quad y=0 \rightarrow k \frac{\partial T}{\partial y}+\dot{q}_{t, i}{ }^{\prime \prime}=0
$$

The heat transfer by radiation of the flames, $\dot{q}_{f, i}{ }^{\prime \prime}$, can be calculated as follows [9]: $\dot{q}_{f, i}=\varepsilon_{f} \sigma F_{v-i}\left(T_{f}^{4}-T_{s, i}^{4}\right)$

A constant value or a value depending on the smoke production of the material [10] is assumed for the emissivity of the flame, $\varepsilon_{f}$. A constant value of $1300 \mathrm{~K} \mathrm{[11]} \mathrm{is} \mathrm{assumed} \mathrm{for}$ the flame temperature, $T_{f}$. The viewfacor $F_{v-i}$ can be determined by Figure 6 and reference [12].

The flame is represented as a triangle, the base of which is equal to the burning distance given by $\left(x_{p}-x_{b}\right)$. This triangle is bent depending on the orientation of the flow. In the first simulations an angle of $45^{\circ}$ was taken based on visual observations made during the full scale tests. However in the future this angle can be calculated by means of the information from zone or field models in the specific configuration one wishes to investigate. The height of the triangle, $H_{f}$, depends on the height of the flame, which is linked to the heat release produced by the burning area. For practical reasons an exponential representation of the heat release curve was used, similar to previous work performed in the field of wall linings [7].

The relationship between the heat release and the height of the flame is given by the following empirical formula (reference [13]):

$$
\frac{H_{f}}{D}=3.7 Q^{* \frac{2}{5}}-1.02
$$

The external heat flux, $\dot{q}_{e, i}{ }^{\prime \prime}$, is taken as the downward radiation of the smoke gas layer below the ceiling produced by the thermal attack in the room. In this model heat fluxes, measured in the reference tests have been used. For a wind-aided flame spread the convective heat transfer, $\dot{q}_{c, i}{ }^{\prime}$, will be the heat transfer from the hot gases produced by the flames and flowing over the surface of the floor covering given as follows [14]:

$\dot{q}_{c, i}{ }^{\prime \prime}=h\left(T_{r f}-T_{s, i}\right)$

The convection coefficient, $h$, can be calculated by applying traditional convective heat transfer theories [14]. The conduction in the gas phase, $\dot{q}_{c o, i}{ }^{\prime \prime}$, is only important near the pyrolysis front and can be calculated using references [2] and [14]. Conductive heat transfer in the gas phase is especially important in wind opposed flame spread [15]. For wind-aided 
flame spread this factor can be neglected relative to the radiation from the flame as can be shown in a simplified heat transfer calculation [2].

Radiation heat losses at the surface, $\dot{q}_{r, i}{ }^{\prime \prime}$, are given by :

$\dot{q}_{r, i}^{\prime \prime}=-\varepsilon_{s} \sigma\left(T_{s, i}^{4}-T_{\infty}^{4}\right)$

where the emissivity of the surface, $\varepsilon_{s}$, depends on the type of material. For this model a mean value of 0.9 has been taken [14]. Radiation losses are only important at higher temperatures, i.e., when the material reaches its ignition temperature.

The pyrolysis front is calculated by calculating the surface temperature of the material and comparing it with the corresponding surface ignition temperature for the material $T_{i g}$. This means that for each strip $i$ the surface temperature is calculated by means of the numerical solution of the Duhamel integral [16]:

$$
T_{s, i}(t)=T_{\infty}+\int_{0}^{t}\left(\dot{q}_{t, i}{ }^{\prime \prime}(\tau)\right) \cdot \sqrt{\frac{t-\tau}{\pi k \rho c}} d \tau
$$

Two values are necessary for the solution of this integral, namely the apparent $k \rho c$ and the ignition temperature $T_{i g}$. Both values are calculated by means of a set of ignition results in the cone calorimeter at different heat flux levels and by applying the theory developed by Janssens [17]. Since the floor coverings were tested in the cone calorimeter with a grid and using a slightly different substrate, a numerical heat transfer model based on a Cranck Nicholson algorithm was also developed to correct the ignition time for both deviations [2].

\section{Results and discussion}

Table 2 gives an overview of the simulation results including a comparison with the burned length in the full scale test results. In the full scale tests three different thermal attacks were used: first $100 \mathrm{~kW}$ period was applied for 10 minutes, then $300 \mathrm{~kW}$ for a further 10 minutes, followed by a period of $550 \mathrm{~kW}$ until flashover or for a maximum of 40 minutes. A detailed description of the full scale test set-up is given elsewhere [2][3]. Since the total floor covered distance in both room and corridor was $8710 \mathrm{~mm}$ the calculation was stopped when the pyrolysis front reached this distance. In those cases the extinction time corresponded to the time for the front to reach $8710 \mathrm{~mm}$. As can seen in table 2 the prediction of burned length is reasonably good in most cases. Those cases where the prediction is inadequate can be explained in terms of the assumptions or simplifications made for the model:

- For some materials the exponential representation of the heat release curve in the cone calorimeter is not correct (PVC 2 and carpet 3, see figure 7). Since the peak heat release in the cone calorimeter occurs closer to the end of the test, the predictions are more severe.

- Feedback of the radiation of the smoke gases produced by the material is not incorporated in the model. This explains slower predicted flame spread for materials with a high peak heat release (Parquet 3). 
Considering that about $50 \%$ of the materials are flame retarded, either by flame retarding treatment (FR cork, Carpet 2 and Rubber) or by the chemical nature of the material (PVC 15 ), one can conclude that the model is quite successful in predicting the risk of wind-aided flame spread of floor coverings.

\begin{tabular}{||c|c|c|c|c||}
\hline \hline & \multicolumn{5}{|c|}{ TABLE 2: Results numerical simulation model } \\
\hline Material & $\begin{array}{c}\text { Ignition first strip } \\
\text { in room } \\
\text { (s) }\end{array}$ & $\begin{array}{c}\text { Extinction time } \\
\text { (s) }\end{array}$ & $\begin{array}{c}\text { Burned } \\
\text { Distance } \\
\text { (mmm) }\end{array}$ & $\begin{array}{c}\text { Burned } \\
\text { distance FS } \\
\text { tests (mm) }\end{array}$ \\
\hline PVC 1 & 1542 & 2007 & 1110 & $<1200$ \\
\hline PVC 2 & 1900 & $>3000$ & 6910 & $<1200$ \\
\hline PVC 3 & 1660 & 2053 & 2410 & 6300 \\
\hline PVC 4 & 1480 & 1973 & 3410 & 3700 \\
\hline PVC 5 & 1360 & 1869 & 3910 & 2200 \\
\hline Linoleum & 1662 & 2178 & 8710 & 8710 \\
\hline Parquet 1 & 1660 & $>3000$ & 6910 & 4700 \\
\hline Parquet 1 & 1540 & $>3000$ & 5910 & 3700 \\
\hline Parquet 3 & 2440 & $>3000$ & 3510 & 8710 \\
\hline Cork FR & 2920 & 2990 & 3100 & 2900 \\
\hline Carpet 1 & 1900 & 2110 & 1000 & 1700 \\
\hline Carpet 2 & 1302 & 1492 & 8710 & 8710 \\
\hline Carpet 3 & 1242 & 1528 & 8310 & 1700 \\
\hline Carpet 4 & 1662 & 2066 & 8710 & 8710 \\
\hline Carpet 5 & 1962 & 2533 & 8710 & 8710 \\
\hline Carpet 6 & 1422 & 1770 & 8710 & 8710 \\
\hline Rubber & 1720 & $>3000$ & 2110 & 1700 \\
\hline
\end{tabular}

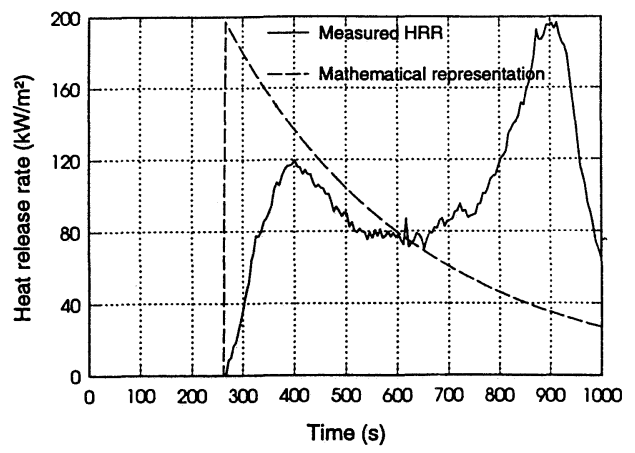

FIGURE 7: Comparison of exponential representation of the heat release curve and the real heat release curve for Carpet 3. 


\section{CONCLUSIONS}

Two mathematical flame spread models for the prediction of wind-aided flame spread of floor coverings are presented based on the approach used for wall and ceiling linings. This approach is applied for the first time to floor coverings by taking into account specific assumptions related to horizontal wind-aided flame spread. An analytical model can be used for a fast and easy way to evaluate the risk of a given floor covering. A drawback of this solution is its limitation to a specific scenario. A numerical model has been developed for use when the flame spread needs to be calculated for varying conditions. If necessary, this model can be integrated in the future into a zone or field model to predict the fire development of a floor lining. These types of submodels are still lacking in zone and field models. Both models use only material characteristics determined in the cone calorimeter and show acceptable levels of accuracy comparable with those found in models used for the prediction of upward flame spread of wall linings.

The following improvements are suggested as future work:

- the use of the exact heat release curve, and

- the inclusion of the feedback of the radiation by the smoke gases produced by the material itself by using integration of the model in field and zone models.

\section{ACKNOWLEDGEMENTS}

This article is part of a Ph.D. dissertation performed at the University of Gent. The author would like to thank the University of Gent and in particularly Prof. Minne and Prof. Vandevelde for assisting him during his work. The author would also like to thank the Swedish National Testing and Research Institute for allowing him to prepare and present this paper.

\section{NOMENCLATURE}

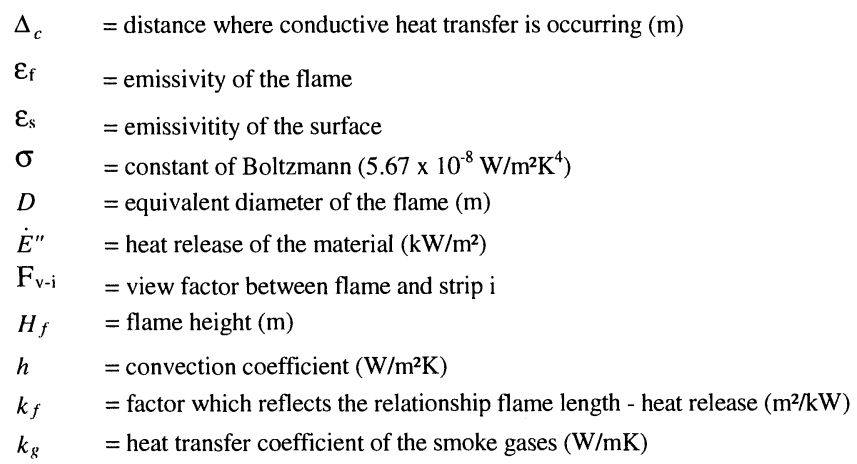


$Q^{*} \quad=$ a non dimensional factor for the heat release

$\dot{q}_{c, i}{ }^{\prime} \quad=$ heat transfer by convection at the surface of strip i $\left(\mathrm{W} / \mathrm{m}^{2}\right)$

$\dot{q}_{c o, i}{ }^{\prime \prime} \quad=$ heat transfer by conduction through the gas phase towards strip $\mathrm{i}\left(\mathrm{W} / \mathrm{m}^{2}\right)$

$\dot{q}_{e, i}{ }^{\prime} \quad=$ external heat flux from thermal attack, e.g. radiation of hot smoke gas layer under the ceiling $\left(\mathrm{W} / \mathrm{m}^{2}\right)$

$\dot{q}_{f, i}{ }^{\prime \prime} \quad=$ incident radiative heat flux from the flame $\left(\mathrm{W} / \mathrm{m}^{2}\right)$

$\dot{q}_{r, i}{ }^{\prime \prime} \quad=$ heat losses at the surface of strip i (negative term) $\left(\mathrm{W} / \mathrm{m}^{2}\right)$

$\dot{q}_{t, i}{ }^{\prime \prime} \quad=$ total incident heat flux on strip $\mathrm{i}\left(\mathrm{W} / \mathrm{m}^{2}\right)$

$T_{f} \quad=$ the flame temperature $(\mathrm{K})$

$T_{r f} \quad=$ temperature of the smoke gases from the flame (K)

$T_{s, i} \quad=$ surface temperature of strip $\mathrm{i}(\mathrm{K})$

$T_{\infty} \quad=$ ambient temperature $(\mathrm{K})$

$x_{f} \quad=$ flame length $(\mathrm{m})$

$x_{p} \quad=$ pyrolysis distance $(\mathrm{m})$

\section{REFERENCES}

1. J.G. Quintiere, "Surface spread of flame", The SFPE Handbook of Fire Protection, First edition, Chapter 1.24, pp. 1.360-1.367, NFPA, 1988.

2. P. Van Hees, "Wind-aided flame spread of floor coverings. Development and validation of large scale and small scale test methods", University of Gent (in Dutch), 1995.

3. P. Van Hees, P. Vandevelde, "Wind-aided flame spread of floorcoverings. Development and validation of large and small scale tests", Interflam 1996 proceedings, pp. 57-67, Interscience Communications Ltd, 1996.

4. F. Mowrer, R. Williamson, "Flame spread evaluation for thin interior finish materials", Proceedings of the third IAFSS Symposium, pp. 689-698, Elsevier Applied Science, 1991.

5. Saito, K, Quintiere, J.G., Williams, F.A., "Upward Turbulent Flame Spread", Proceedings First International Symposium on Fire Safety Science, Hemisphere Publishing Corporation, New York, 1984.

6. Thomas, P.H., Karlsson, B., "On Upward Flame Spread On Thick Fuels", Report LUTVDG/TVBB 3058, Department of Fire Safety Engineering, Lund University, Lund, 1992.

7. B. Karlsson, "Modeling fire growth on combustible lining materials in enclosures", Lund University, Report TVBB-1009, Lund, 1992.

8. J.P. Holman, "'Heat Transfer", Mc Graw Hill Book Company, 1989.

9. R. Siegel, J. Howell, 'Thermal radiation heat transfer", Hemisphere Publishing Co., New York, 1981.

10. Q. Jianmin, 'Prediction of flame spread test results from the test data of the Cone Calorimeter", SP report 1990:38, Swedish National Testing and Research Institute, 1990.

11. D. Drysdale, "An introduction to fire dynamics", John Wiley \& Sons Ltd, 1985.

12. T. Love, "Radiative Heat Transfer", Charles E. Merrill Publishing Company, Colombus, Ohio, 1968.

13. B. McCaffrey, "Flame height", The SFPE Handbook of Fire Protection, First edition, Chapter 1.18, pp. 1.298-1.305, NFPA, 1988.

14. R. Minne, P. Vandevelde, 'Heat Transfer Course I", University of Gent (in Dutch), Gent, 1994.

15. J.G. Quintiere, M. Harkleroad, "New concepts for measuring flame spread properties", NBSIR 84-2943, NIST, Washington, 1984.

16. M. Özisik, "Heat conduction", Wiley-Interscience publication, p. 194, John Wiley \& Sons, 1980.

17. M. Janssens, "'Fundamental thermophysical characteristics of wood and their role in enclosure fire growth", Faculteit van de Toegepaste Wetenschappen, University of Gent, Gent, 1991. 